See discussions, stats, and author profiles for this publication at:

http://www.researchgate.net/publication/221977764

\title{
An Examination of the Psychopathic Personality Inventory's Nomological Network: A Meta-Analytic Review
}

ARTICLE in PERSONALITY DISORDERS: THEORY, RESEARCH, AND TREATMENT • AUGUST 2011

Impact Factor: $3.54 \cdot$ DOI: $10.1037 /$ a0024567 · Source: PubMed

CITATIONS

66
READS

146

\section{AUTHORS:}

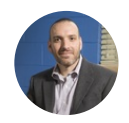

Joshua D Miller

University of Georgia

155 PUBLICATIONS 4,025 CITATIONS

SEE PROFILE

Donald R Lynam

Purdue University

159 PUBLICATIONS 9,778 CITATIONS

SEE PROFILE 


\title{
FEATURED ARTICLE
}

\section{An Examination of the Psychopathic Personality Inventory's Nomological Network: A Meta-Analytic Review}

\author{
Joshua D. Miller \\ University of Georgia
}

\author{
Donald R. Lynam \\ Purdue University
}

\begin{abstract}
Since its publication, the Psychopathic Personality Inventory and its revision (Lilienfeld \& Andrews, 1996; Lilienfeld \& Widows, 2005) have become increasingly popular such that it is now among the most frequently used self-report inventories for the assessment of psychopathy. The current meta-analysis examined the relations between the two PPI factors (factor 1: Fearless Dominance; factor 2: Self-Centered Impulsivity), as well as their relations with other validated measures of psychopathy, internalizing and externalizing forms of psychopathology, general personality traits, and antisocial personality disorder symptoms. Across 61 samples reported in 49 publications, we found support for the convergent and criterion validity of both PPI factor 2 and the PPI total score. Much weaker validation was found for PPI factor 1, which manifested limited convergent validity and a pattern of correlations with central criterion variables that was inconsistent with many conceptualizations of psychopathy.
\end{abstract}

Keywords: psychopathy, assessment, fearless dominance, self-centered impulsivity

Psychopathy is one of the most frequently empirically examined and well-validated personality disorders (PDs), despite not being officially included in the most recent diagnostic taxonomy, the Diagnostic and Statistical Manual of Mental Disorders (DSM-IV-TR; APA, 2000). Influenced by a number of prominent theorists including Cleckley (1941/ 1988), Hare (e.g., 1991), Karpman (1941) and Lykken (1957, 1995), psychopathy is thought to comprise personality traits such as manipulativeness, egocentricity, callousness, a lack of remorse or empathy, impulsivity and irresponsibility, as well as a pervasive and early involvement in criminal behavior (cf., Cooke $\&$ Michie, 2001). Numerous studies have doc-

\footnotetext{
This article was published Online First August 8, 2011.

Joshua D. Miller, Department of Psychology, University of Georgia, Athens; Donald R. Lynam, Department of Psychological Sciences, Purdue University.

Both authors contributed equally to this work.

Correspondence concerning this article should be addressed to Joshua D. Miller, Department of Psychology, University of Georgia, Athens, GA 30602-3013; or Donald R. Lynam, Department of Psychological Sciences, Purdue University, West Lafayette, IN 47906. E-mail: jdmiller@uga.edu or dlynam@purdue.edu
}

umented the relation between psychopathy and a vast array of externalizing behaviors such as crime and aggression in adults (e.g., Porter, Birt, \& Boer, 2001) and juveniles (e.g., Gretton, Hare, \& Catchpole, 2004), criminal recidivism (e.g., Walters, Knight, Grann, \& Dahle, 2008), substance use (e.g., Gustavson et al., 2007; Kennealy, Hicks, \& Patrick, 2007), and sexual offending (Caldwell, Ziemke, \& Vitacco, 2008).

The most frequently used and empirically validated assessment tool for psychopathy is the Psychopathy Checklist (PCL; Hare, 1991) and its revision (PCL-R; Hare, 2003), particularly when assessing psychopathy among incarcerated offenders. Until recently (see Cooke \& Michie, 2001), PCL/PCL-R psychopathy was thought to be composed of two factors that were correlated at approximately .50 (Hare, 1991). Factor $1(\mathrm{~F} 1)$ is related to the interpersonal and affective components of psychopathy (e.g., grandiosity, lying, callousness), whereas factor 2 (F2) comprises traits and behaviors indicative of "social deviance" (e.g., juvenile delinquency, impulsivity; Hare, 1991). The PCL/ PCL-R factors often manifest differential patterns of relations with external criteria. For 
instance, F1 has been unrelated or weakly negatively associated with psychological distress and anxiety (e.g., Harpur, Hare, \& Hakstian, 1989; Schmitt \& Newman, 1999) and positively associated with social dominance (e.g., Harpur et al., 1989), narcissism and narcissistic PD (e.g., Blackburn \& Coid, 1998; Hildebrand \& de Ruiter, 2004), and emotional detachment (e.g., Patrick, Bradley, \& Lang, 1993), whereas F2 has been positively associated with violence, criminality, borderline PD (BPD) and antisocial PD (APD; e.g., Blackburn \& Coid, 1998; Hare, 1991; Skeem \& Mulvey, 2001), recidivism (e.g., Hemphill, Hare, \& Wong, 1998), substance use (e.g., Taylor \& Lang, 2006), and distress (e.g., Verona, Patrick, \& Joiner, 2001).

The psychopathy factors also differ with regard to the general personality traits that underlie each construct. From a Five-Factor model (FFM) approach, both psychopathy factors are substantially related to an antagonistic interpersonal style (FFM Antagonism) and some degree of impulsivity/disinhibition (FFM Conscientiousness). The factors differ, however, in that F2 is more strongly related to impulsivity/ disinhibition and indices of negative emotionality (which are usually unrelated to F1 measures of psychopathy; see Lynam \& Derefinko, 2006).

\section{Self-Report Psychopathy Instruments}

Despite its many advantages, there are aspects of the PCL-R that limit its utility as an assessment in certain circumstances. These limitations include a) the need for extensive training prior to use of the PCL-R, b) use of a lengthy interview, and c) access to file information pertaining to official criminal records and institutional behavior prior to scoring the PCL-R. Unfortunately, interviews of this sort are not always practical and institutional files are not readily available outside of institutional settings. In response to these limitations, several self-report measures have been developed to assess psychopathy in these populations. These measures differ, however, in the degree to which they were designed to be congruent with the PCL-R. For example, self-report measures such as the Self-Report Psychopathy Scale (SRP: Hare, 1985; SRP-III: Williams, Paulhus, \& Hare, 2007), the Levenson Self-Report Psychopathy Scale (LSRP: Levenson, Kiehl, \&
Fitzpatrick, 1995), and the Antisocial Process Screening Device (APSD: Frick \& Hare, 2001) were designed to assess psychopathy from a PCL-R perspective, and thus typically manifest a factor structure that is thought to be somewhat consistent with the PCL-R. Alternatively, the Psychopathic Personality Inventory (PPI; and revised, [PPI-R] Lilienfeld \& Andrews, 1996; Lilienfeld \& Widows, 2005) was created by including items derived from a variety of conceptualizations of psychopathy (see Lilienfeld \& Andrews, 1996, for details). We turn our attention to this self-report measure of psychopathy as it has rapidly become one of the most popular and frequently used measure of psychopathy.

\section{PPI/PPI-R}

The PPI was developed as the result of an iterative test construction approach in which items and the resultant scales were regularly revisited and reworked "until both a well formulated set of constructs and an adequate pool of items to assess them is achieved" (Lilienfeld \& Andrews, 1996, p. 490). The PPI/PPI-R (referred to as the PPI from here on out) includes the following eight subscales: Machiavellian Egocentricity, Rebellious Nonconformity, Blame Externalization, Carefree Nonplanfulness, Social Influence, Fearlessness, Stress Immunity, and Coldheartedness. The PPI's ability to parse psychopathy into a number of narrow, lower-order constructs offers much promise, utility, and novelty as a means of understanding how the various components of psychopathy converge and diverge in relation to important aspects of psychopathy's nomological network. This more "atomic" approach is quite consistent with our own research in which we have worked to understand psychopathy using traits from a general model of personality (e.g., Lynam \& Widiger, 2007; Miller, Lynam, Widiger, \& Leukefeld, 2001). Unfortunately, research using the PPI has moved from a focus on these eight factors to the use of two higher-order factors that have been titled Fearless Dominance (PPI FD) and Self-Centered Impulsivity (PPI ScI; Benning, Patrick, Hicks, Blonigen, \& Krueger, 2003; Lilienfeld \& Widows, 2005; cf., Neumann, Malterer, \& Newman, 2008). One of the PPI subscales, Coldheartedness, does not load on either of these two factors and is often ex- 
cluded from empirical studies that use the PPI (Edens, Poythress, Lilienfeld, Patrick, \& Test, 2008; Patrick, Edens, Poythress, Lilienfeld, \& Benning, 2006). This exclusion is unfortunate given the centrality of coldheartedness to traditional descriptions of psychopathy, the significant correlations between this subscale and other self-report psychopathy scales (e.g., Derefinko \& Lynam, 2006; Gaughan, Miller, Pryor, \& Lynam, 2009), and its associations with other traits central to psychopathy (i.e., antagonism; Derefinko \& Lynam, 2006; Seibert, Miller, Few, Zeichner, \& Lynam, in press).

The PPI is fast becoming the most commonly used self-report measure of psychopathy. This measure and associated conceptualization of psychopathy has become so prominent that a number of recent studies have been published in which the primary aim is the development of proxy measures for the two PPI factors using general models of personality including the Multidimensional Personality Questionnaire (MPQ; Benning, Patrick, Blonigen, Hicks, \& Iacono, 2005), the Revised NEO Personality Questionnaire (NEO PI-R; Witt et al., 2010), HEXACO Personality Inventory, and the IPIPNEO (Witt, Donnellan, \& Blonigen, 2009). Authors of these proxy measures of the PPI suggest that these projects are important because it allows an examination of psychopathy in numerous data sets that were not designed to study psychopathy but included these comprehensive, general measures of personality (e.g., MPQ; NEO PI-R; Witt et al., 2010). The growing stature of the PPI is also reflected in the fact that the PPI has even been called "the gold standard self-report psychopathy measure" (Witt, Donnellan, \& Blonigen, 2009, p. 1007).

Although there is evidence to support the general validity of the PPI ScI factor, there is an important issue regarding the PPI FD factor which we believe remains to be addressed; namely, what exactly is being measured by this factor? Some researchers, including ourselves, have raised concerns regarding the validity of FD as an indicator of psychopathy. These concerns are based on two primary issues: 1) the convergent correlations manifested by PPI FD with other psychopathy measures and 2) whether the external correlates of PPI FD provide a conceptual and/or empirical fit with the psychopathy construct. With regard to point 1 , PPI FD typically manifests limited correlations with PCL-R scores (e.g., Malterer, Lilienfeld, Neumann, \& Newman, 2010; Zolondek, Lilienfeld, Patrick \& Fowler, 2006), as well as other self-report measures such as the LSRP and SRP-III (e.g., Gaughan et al., 2009; cf., Benning, Patrick, Blonigen, et al., 2005). In fact, factor analyses suggest that PPI FD does not load with other putatively similar psychopathy factors (Gaughan et al., 2009; Seibert et al., in press). With regard to point 2, the PPI FD, depending on one's conceptualization of psychopathy, fails to manifest correlations with measures of many of the constructs typically thought to be central to psychopathy such as externalizing behaviors including antisocial behavior (ASB), substance use, and aggression, interpersonal antagonism, callousness, and disinhibition (e.g., Blonigen et al., 2010; Witt et al., 2010). Instead, PPI FD appears to demonstrate its strongest correlations with symptoms of psychological distress and internalizing disorders (negative correlations: Blonigen et al.; Sellbom, Ben-Porath, Lilienfeld, Patrick, \& Graham, 2005; Witt et al.) and traits of positive emotionality, extraversion, and sensation seeking (positive correlations: Derefinko \& Lynam, 2006; Gaughan et al., 2009; Ray, Poythress, Weir, \& Rickelm, 2009).

Even among those who accept the basic validity of the PPI-FD factor, there is little consensus as to what it represents substantively. Several have argued that PPI FD is a good index of PCL-R F1 (e.g., Benning et al., 2003; Poythress et al., 2010). Benning et al. (2003) concluded "The external correlates of the two PPI factors paralleled associations reported for the two factors of Hare's (1991) PCL-R, which index the emotional-interpersonal and antisocial deviance features of psychopathy as conceptualized by Cleckley (1976) - indicating that the PPI may be useful for assessing these distinct facets of psychopathy via self-report" (p. 346). It has also been suggested that PPI FD and PCL-R F1 are different in that the PPI FD factor taps "positive adjustment... along with tendencies toward narcissism and emotional sensitivity (Benning, Patrick, Blonigen, et al., 2005), whereas PCL-R factor 1 taps tendencies that are more uniformly deviant" (Edens, Poythress, Lilienfeld, Patrick, \& Test, 2008, p. 89). Recently, some researchers have argued that PPI FD assesses the "mask" of sanity described by Cleckley (e.g., Edens, Poythress, Lilienfeld, 
Patrick, \& Test, 2008). For example, Patrick and colleagues (2006; p. 207) argued that "PPI-I [FD] assesses, at least in part, the convincing "mask" of sanity that Cleckley regarded as central to psychopathy." In a somewhat related argument, Patrick has suggested that PPI FD assesses psychopathic boldness, a trait that is a central part of his triarchical model of psychopathy (e.g., Patrick, 2006). Finally, some have argued that PPI FD may represent a construct more consistent with Lykken's conception of primary psychopathy (Edens, Poythress, Lilienfeld, Patrick, \& Test, 2008).

\section{Current Study}

From a construct validity perspective (Cronbach \& Meehl, 1955), the construct assessed by a measure is understood by the relations it bears to other constructs. To this end, we conducted a meta-analysis of the PPI scales and their relations with core constructs from psychopathy's nomological network. The meta-analysis is necessarily guided by the extant empirical literature; we included constructs for which there were six or more effect sizes. Because most studies of the PPI have been organized around the nomological network generated by research using Hare's PCL and PCL-related measures (e.g., PCL-R; PCL: SV), the current metaanalysis is similarly organized. For example, in earlier work, Benning et al. (2003) "hypothesized that two dominant factors would emerge from the PPI and that these factors would exhibit distinct diagnostic, demographic, and personality correlates paralleling those found for the two factors of the PCL-R" (p. 342). More recently, Poythress and colleagues (2010) "used the PCL-R to help estimate the validity of two self-report measures of psychopathy" (p. 206) by comparing the pattern of correlates generated by the PPI and LSRP with those generated by the PCL-R. In the latter study, the PCL-R correlates were explicitly used as "benchmarks for the validation" of these two self-report measures because "the PCL-R is currently the most extensively validated measure of psychopathy" (p. 214). Thus, the nomological network framing the meta-analysis is primarily the one surrounding the PCL/PCL-R.

Although we are driven to this particular nomological network primarily by the available literature, such a network is defensible.
Hare's model and measures of psychopathy are largely consistent with Cleckley's important conceptualization of psychopathy (e.g., 1941), although there are some divergences (see Hare \& Neumann, 2008, for a review). Second, Hare's conceptualization of psychopathy is linked to traits and behaviors such as crime, violence, and recidivism that we believe are responsible for the enormous clinical and research interest in the construct. Finally, by virtue of being the most extensively validated psychopathy assessment, as noted by Poythress et al. above, it is likely to be the most familiar to readers. We acknowledge that others might object to the nomological network used here since it includes, to a significant degree, an emphasis on psychopathy's relations with externalizing behaviors. Other researchers might prefer an alternative network built instead on theoretical accounts such as those offered by Lykken (e.g., 1957; 1995) or Fowles (e.g., Fowles \& Dindo, 2006). We believe these disagreements about the appropriate nomological net are simply a reflection of the active debates within the field of psychology around the question of what is psychopathy. As the body of research continues to accumulate, many more correlates may be included.

In this meta-analysis, we first examine the relations between the PPI factors and alternative assessments of psychopathy including the PCL/ PCL-R, LSRP, SRP, and ASPD. Second, we analyze the relations between the PPI factors and internalizing symptoms (e.g., anxiety) and externalizing behaviors (e.g., ASB, aggression). Third, we examine the relations between the PPI factors and personality traits from general models of personality (e.g., FFM; MPQ; BIS/ BAS) and individual traits (e.g., impulsivity, empathy). More specifically, we review the relations between the PPI factors and the domains from the FFM, Tellegen's three-factor model of personality, behavioral activation/inhibition (BIS/BAS), sensation seeking, impulsivity, and empathy. Fourth, we review the relations between the PPI factors, APD, BPD, and narcissism/narcissistic PD (NPD). Finally, we test for the existence of statistical moderators for effect sizes that proved to be significantly heterogeneous. 


\section{Method}

We conducted a comprehensive search for empirical research regarding the relations between the PPI and relevant criterion variables. We did this by searching PsycINFO and reviewing all published articles that used the PPI. In addition, we reviewed the references of these studies in order to identify any publications that may have been missed. We did not include dissertations or solicit unpublished data for the current review. Studies that reported relevant relations using several different samples were treated as independent samples, and each was included in the meta-analysis. In some studies, several effect sizes were included that fell into the same category (e.g., different forms of aggression or substance use); in these cases, an average correlation was used. Because our interest lay primarily in the two factors of the PPI, to be included in the meta-analysis, studies must have reported on the relations for the individual scales. See Table 1 for the studies included in the current meta-analysis.

\section{Results}

Across studies, effect sizes for seven general categories of effects were retrieved: correlations between PPI factors, relations to other psychopathy indices, internalizing psychopathology, externalizing psychopathology, structural models of personality, individual personality traits, and personality disorders. Thirty specific outcomes were examined within these general categories. Effect sizes were coded as Pearson correlation coefficients which were transformed using Fisher's $\mathrm{Z}_{\mathrm{r}}$-transform (Hedges \& Olkin, 1985). As noted earlier, if a study provided more than one effect size per outcome, effects were averaged in order to produce a single effect size per study sample. Two of the broader outcomes, internalizing and externalizing psychopathology, represent averages of multiple other effects. The internalizing effect size represents the average of anxiety, fear, and mood effect sizes, whereas the externalizing effect represents the average of ASB, aggression, and substance use. Additionally, some studies reported only the correlations between PPI factors and the factors of other psychopathy indices but did not report the correlations between PPI factors and total psychopathy scores. In these cases, effect sizes for psychopathy factors were averaged to provide a total score effect size. Similarly, a few studies reported the correlations between PPI factor scores and the BAS subscales, but not the overall BAS scale; in these cases, effect sizes for the subscales were averaged to produce an overall BAS effect size.

Across studies, several potential moderators were identified and coded for each study. These included percent of participants who were male, percent of participants who were Caucasian, average age of the sample, whether the sample was from a forensic or clinical setting versus an undergraduate or community sample, whether the other measures of psychopathy employed used a variant of the Psychopathy ChecklistRevised versus one or more self-reports, whether reports of APD and NPD were based explicitly on DSM criteria or rating scales, and which version of the PPI was used (i.e., original, revised, short form, or estimated).

Weighted effect sizes were computed for each outcome category for which at least six effect sizes were available. Table 2 provides these results for both PPI factors along with the number of effect sizes, total number of participants, standard errors and 95\% confidence intervals. ${ }^{1}$ Across 37 effect sizes, there is a significant ${ }^{2}$ but small positive correlation of .05 between PPI FD and PPI ScI. There were significant positive relations between both factors of the PPI and the two factors of other psychopathy scales. PPI FD was more strongly related to factor 1 indices $(r=.23)$ than to factor 2 indices $(r=.07)$, whereas PPI ScI was more strongly related to factor 2 indices $(r=.56)$ than to factor 1 indices $(r=$ .38). However, PPI ScI was more strongly related to each psychopathy factor than was PPI FD, and also more strongly related to the total scores from other psychopathy indices ( $r \mathrm{~s}=.16$ and .51 for PPI FD and ScI, respectively). The confidence intervals for the two PPI factors were nonoverlapping for each of these outcomes.

\footnotetext{
${ }^{1}$ We employed a fixed effects rather than a random effects model because we believe the differences in effect sizes are likely to vary systematically across studies as functions of study characteristics. However, results are quite similar if a random effects analysis is used.

${ }^{2}$ Statistical significance is indicated by the fact that the 95\% confidence does not include zero.
} 
Table 1

Study Included in the Meta-Analysis and Sample Characteristics

\begin{tabular}{|c|c|c|c|c|}
\hline & $N$ (range) & Sample type & PPI measure & Outcome(s) \\
\hline \multicolumn{5}{|l|}{ Baskin-Sommers, Zeier, \& } \\
\hline Newman (2009) & 473 & Prison & PPI-SF & $1,2,3$ \\
\hline $\begin{array}{l}\text { Benning, Patrick, Blonigen, } \\
\text { et al. (2005) }\end{array}$ & 1049 & Community & MPQ-estimated & $1,5,6$ \\
\hline $\begin{array}{l}\text { Benning, Patrick, Blonigen, } \\
\text { et al. (2005) }\end{array}$ & 346 & Student & MPQ-estimated & $1,5,7,9,11,12,13$ \\
\hline $\begin{array}{l}\text { Benning, Patrick, Blonigen, } \\
\text { et al. (2005) }\end{array}$ & $69-218$ & Prison & MPQ-estimated & $2,3,5,6,7,9,11,12,13$ \\
\hline $\begin{array}{l}\text { Benning, Patrick, Hicks, et } \\
\text { al. (2003) }\end{array}$ & 353 & Community & PPI & 6,7 \\
\hline $\begin{array}{l}\text { Benning, Patrick, Salekin, } \\
\text { et al. (2005) }\end{array}$ & 326 & Student & PPI & $1,2,3,5,12,13,14$ \\
\hline Berardino et al. (2005) & 105 & Prison & PPI-SF & $1,2,3,4,5,12$ \\
\hline Blonigen et al. (2010) & 1741 & Prison & PPI & $1,2,3,4,5,6$ \\
\hline \multicolumn{5}{|l|}{ Chapman, Gremore, \& } \\
\hline Farmer (2003) & 36 & Prison & PPI & 12 \\
\hline Claes et al. (2009) & 399 & Psychiatric patients & PPI & $6,8,12,13$ \\
\hline $\begin{array}{l}\text { Del Gaizo \& Falkenbach } \\
\text { (2008) }\end{array}$ & 175 & Student & PPI & 11 \\
\hline \multicolumn{5}{|l|}{ Denson, White, \& } \\
\hline Warburton (2009) & 100 & Student & PPI-R & 6 \\
\hline Derefinko \& Lynam (2006) & 346 & Student & PPI & $1,2,3,6,7,8$ \\
\hline \multicolumn{4}{|l|}{ Edens \& McDermott } & $1,2,3,4,5,6,8$ \\
\hline $\begin{array}{l}\text { Edens, Poythress, } \\
\text { Lilienfeld, \& Patrick } \\
\text { (2008) }\end{array}$ & 50 & Prison & PPI & $1,2,3,4,6$ \\
\hline $\begin{array}{l}\text { Edens, Poythress, } \\
\text { Lilienfeld, Patrick, \& } \\
\text { Test (2008) }\end{array}$ & 131 & Prison & PPI & 1,6 \\
\hline Eisenbarth et al. (2008) & 69 & $\begin{array}{l}\text { Psychiatric patients } \\
\text { and controls }\end{array}$ & PPI-R & 6 \\
\hline $\begin{array}{l}\text { Falkenbach, Poythress, } \\
\text { Falki, \& Manchak } \\
\text { (2007) }\end{array}$ & 96 & Student & PPI & $1,2,3,4,5,6$ \\
\hline Fowler \& Lilienfeld (2007) & 65 & Student & PPI-SF & $1,2,3,4,7,12$ \\
\hline Fulton et al. (2010) & 511 & Student & PPI & 1,9 \\
\hline Gaughan et al. (2009) & 217 & Student & PPI-R & $1,2,3,4,6,7$ \\
\hline Helfritz \& Stanford (2006) & 40 & Student & PPI-SF & 6 \\
\hline $\begin{array}{l}\text { Howard, Balster, Cottler, } \\
\text { Wu, \& Vaughan (2008) }\end{array}$ & 723 & $\begin{array}{l}\text { Division of Youth } \\
\text { Services }\end{array}$ & PPI-SF & 6 \\
\hline Justus \& Finn (2007) & 99 & Community & PPI-SF & $5,7,8,9,12$ \\
\hline Kruh et al. (2005) & 50 & Insanity acquittees & PPI & $2,3,4,6$ \\
\hline \multicolumn{5}{|l|}{ Lilienfeld \& Andrews } \\
\hline (1996)-a & 113 & Student & PPI & 7 \\
\hline \multicolumn{5}{|l|}{ Lilienfeld \& Andrews } \\
\hline \multicolumn{5}{|l|}{ Lilienfeld \& Widows } \\
\hline \multicolumn{5}{|l|}{ Lilienfeld \& Widows } \\
\hline (2005)-b & 154 & Offender & PPI-R & $2,3,4,5,6,12,14$ \\
\hline Lynam et al. (2011) & 345 & Student & PPI-R & 1,7 \\
\hline Malterer et al. (2010)-a & 876 & Prison & PPI & $1,2,3,4$ \\
\hline Malterer et al. (2010)-b & 247 & Prison & PPI & $1,2,3,4$ \\
\hline Malterer et al. (2010)-c & 130 & Student & PPI & $1,2,3,4$ \\
\hline \multicolumn{5}{|l|}{ Mullins-Nelson, Salekin, \& } \\
\hline Leistico (2006) & 174 & Student & PPI-SF & $1,6,11$ \\
\hline
\end{tabular}


Table 1 (continued)

\begin{tabular}{|c|c|c|c|c|}
\hline & $N$ (range) & Sample type & PPI measure & Outcome(s) \\
\hline Ostrov \& Houston (2008) & 679 & Student & PPI-SF & $1,6,12,14$ \\
\hline Patrick et al. (2006)-a & 96 & Prison & PPI & $1,6,11,14$ \\
\hline Patrick et al. (2006)-b & 89 & Prison & PPI & $1,5,6,12,14$ \\
\hline Poythress et al. (2010) & 1472 & Prison/drug treatment & PPI & 1,2 \\
\hline $\begin{array}{l}\text { Pryor, Miller, \& Gaughan } \\
\text { (2009) }\end{array}$ & 229 & Student & PPI-R & $1,2,3,4,7$ \\
\hline Ray et al. (2009) & 92 & Prison & PPI-R & 8,9 \\
\hline Rilling et al. (2007) & 30 & Student & PPI-SF & $1,2,3,4$ \\
\hline $\begin{array}{l}\text { Ross, Benning, Patrick, } \\
\text { Thompson, \& Thurston } \\
\text { (2009) }\end{array}$ & 293 & Student; Prison & PPI & $1,2,3,7,10$ \\
\hline Ross et al. (2007) & 326 & Student & PPI-R & 10 \\
\hline Schmeelk, Sylvers, \& & & & & \\
\hline Lilienfeld (2008) & 220 & Student & PPI-SF & 7 \\
\hline Seibert et al. (in press) & 134 & Student & PPI-R & $1,2,3,4,6,7,8,9,10,12$ \\
\hline Sellbom et al. (2005) & 281 & Student & PPI & $5,7,12$ \\
\hline Sellbom \& Verona (2007) & 95 & Student & PPI & 1,8 \\
\hline Uzieblo et al. (2007)-a & 165 & Prison & PPI & 1,10 \\
\hline Uzieblo et al. (2007)-b & 431 & Student & PPI & 1,10 \\
\hline Uzieblo et al. (2007)-c & 120 & Student & PPI & 5,6 \\
\hline $\begin{array}{l}\text { Uzieblo, Verschuere, Van } \\
\text { den Bussche, \& }\end{array}$ & & & & \\
\hline Crombez (2010) & 675 & Community & PPI-R & $1,2,3,4,5,6,10,11$ \\
\hline $\begin{array}{l}\text { Vaughan, Newhill, DeLisi, } \\
\text { Beaver, \& Howard } \\
\text { (2008) }\end{array}$ & 94 & DYS residents & PPI-SF & 6 \\
\hline $\begin{array}{l}\text { Wilson, Miller, Zeichner, } \\
\text { Lynam, \& Widiger } \\
\text { (2010) }\end{array}$ & 116 & Student & PPI-R & $1,2,3,4,6,7,8,9,10$ \\
\hline Witt \& Donnellan (2008)-a & 416 & Student & MPQ-estimated & $1,2,3,4,6,8,12,13$ \\
\hline $\begin{array}{l}\text { Witt \& Donnellan (2008)-b } \\
\text { Witt, Donnellan, \& }\end{array}$ & 509 & Student & MPQ-estimated & $1,12,13$ \\
\hline Blonigen, (2009) & 143 & Student & IPIP-estimated & 6 \\
\hline $\begin{array}{l}\text { Witt, Donnellan, Blonigen } \\
\text { et al. (2009)-a }\end{array}$ & 304 & Student & PPI-R & $1,2,3,4$ \\
\hline $\begin{array}{l}\text { Witt, Donnellan, Blonigen } \\
\text { et al. (2009)-b }\end{array}$ & 405 & Student & MPQ-estimated & $1,2,3,4,10,13$ \\
\hline $\begin{array}{l}\text { Witt, Donnellan, Blonigen } \\
\text { et al. (2009)-c }\end{array}$ & 432 & Community & MPQ-estimated & $1,5,6$ \\
\hline Witt et al. (2010) & 733 & Clinical & NEO PI-R estimated & $1,5,6,7,12,13,14$ \\
\hline Zolondek et al. (2006) & 93 & Prison & MPQ-estimated & $2,3,4$ \\
\hline
\end{tabular}

Note. Lower-case letters next to citations refer to different studies or samples that were presented within the same citation. $1=$ PPI factor intercorrelations; $2=$ Psychopathy factor $1 ; 3=$ Psychopathy factor $2 ; 4$ = Psychopathy total; $5=$ Internalizing correlates; $6=$ Externalizing correlates; $7=$ Personality models (FFM; MPQ); $8=$ Impulsivity; $9=$ sensation seeking; $10=$ BIS/BAS; $11=$ empathy; $12=$ antisocial personality disorder; $13=$ narcissism/narcissistic personality disorder; 14 = borderline personality disorder.

Significant divergences were observed between PPI FD and ScI in their relations to internalizing problems with nonoverlapping confidence intervals for each outcome examined. Relations were negative and small to moderate in size for PPI FD with average correlations of $-.21,-.35$, and -.34 for problems with negative mood, anxiety, and the general internalizing symptoms domain. In contrast, re- lations for PPI ScI were positive and generally small with average correlations of $.21, .25$, and .29 for mood, anxiety, and the general internalizing domain. Divergences were also observed on indices of externalizing psychopathology as PPI FD manifested a small significant negative relation with aggression (i.e., -.04) and small, statistically significant, positive relations with substance use, ASB, and general externalizing, 


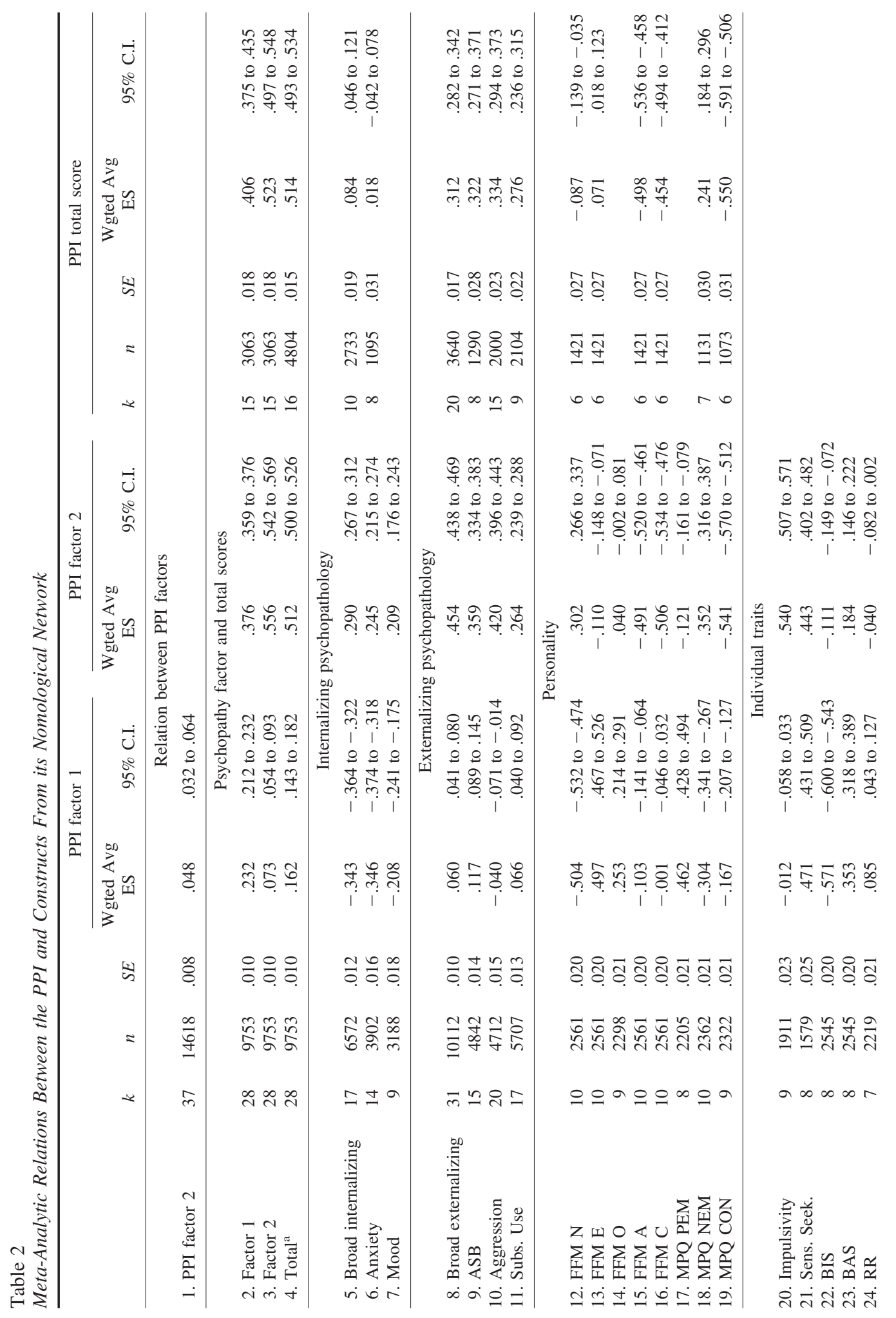




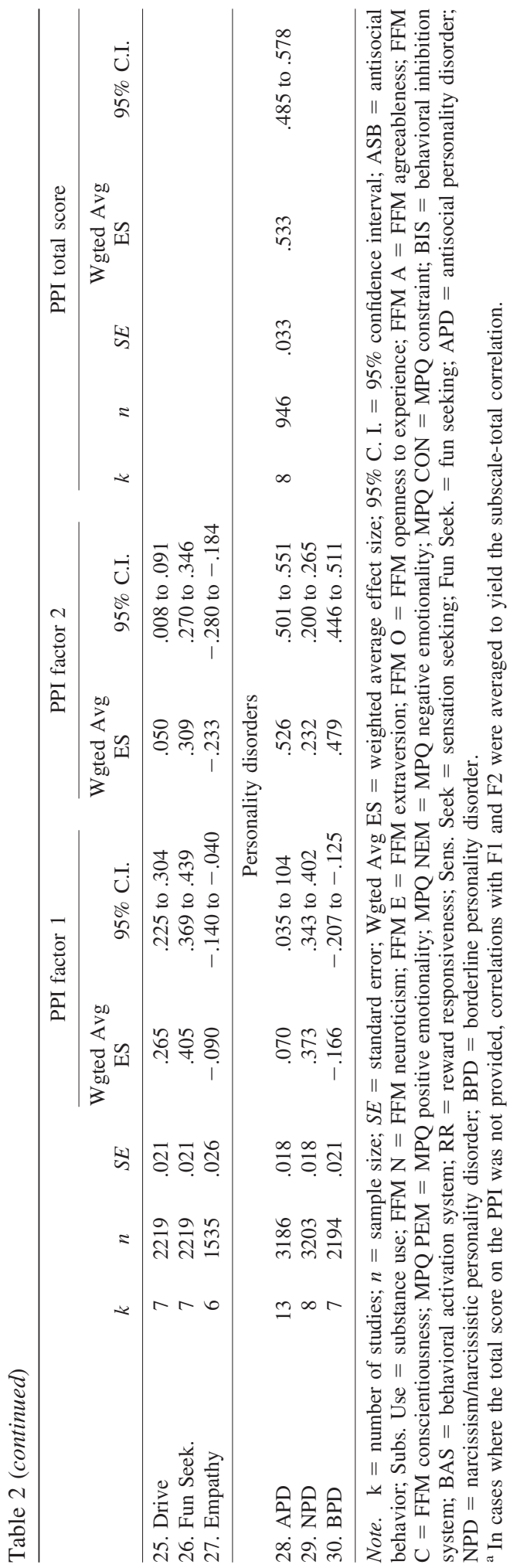

whereas PPI ScI evinced moderate positive relations with all externalizing outcomes ranging from .26 for substance use to .45 for the general externalizing domain.

The pattern of divergent relations was also observed for the personality dimensions from the FFM and MPQ, with the $95 \%$ confidence intervals for PPI FD and ScI showing no overlap. PPI FD was strongly negatively related to Neuroticism $(r=-.50)$ and strongly positively related to Extraversion $(r=.50)$. Additionally, PPI FD evinced moderate positive relations with Openness to Experience and Positive Emotionality, a moderate negative relation with Negative Emotionality, small negative relations with Agreeableness and Constraint, and no relation to Conscientiousness. In contrast, PPI ScI manifested its strongest relations with Conscientiousness/Constraint $(r s=-.51$ and -.54$)$ and Agreeableness $(r=-.49)$. PPI ScI was also significantly positively correlated with Neuroticism and Negative Emotionality. Finally, PPI ScI manifested small negative relations with Extraversion and Positive Emotionality, and no relation to Openness to Experience.

Individual personality traits also demonstrated divergent relations with the two PPI factors, with nonoverlapping confidence intervals for all traits except for sensation seeking, to which both PPI factors were moderately positively related. PPI FD was strongly negatively correlated with the BIS ( $r=$ -.57 ), moderately positively correlated with the BAS and two of its subscales (i.e., Drive and Fun Seeking), and negligibly correlated with impulsivity, BAS -Reward Responsiveness, and empathy. In contrast, PPI ScI was strongly correlated with impulsivity $(r=.54)$, weakly to moderately correlated with BAS and its Fun Seeking subscale (both positive), and empathy (negative), and negligibly correlated with the BIS and the remaining two subscales of the BAS. With regard to personality disorders, PPI FD manifested a small but significant positive correlation with APD $(r=$ .07) compared to a strong positive correlation for PPI ScI $(r=.53)$; both scales were moderately correlated with narcissism/NPD, although the relation was stronger for PPI-FD. Finally, PPI ScI but not PPI-FD was strongly related to BPD. 


\section{Total PPI Scores}

Table 2 also provides meta-analytic results from studies that reported the correlations between PPI total scores and the criterion variables. These relations are examined in order to identify any additive effects that might arise from the simultaneous consideration of FD and $\mathrm{ScI}^{3}{ }^{3}$ In general, there appear to be no additive effects for the total PPI score. With regard to other psychopathy indices, the relations for the PPI total score were slightly larger than those reported for PPI ScI for the two outcomes on which PPI FD shows more than a negligible relation (i.e., factor 1 and Total). Across virtually all other outcomes, the effect size for PPI total falls in between the effect sizes observed for the PPI factors. There are only two exceptions to this finding; each involves an outcome for which each PPI factor bears a non-negligible effect to the outcome in the same directionFFM Agreeableness, and MPQ Constraint. Thus there appears to be little increment in predictive power that comes with the total score.

\section{Moderator Analyses}

For each outcome, except for the individual BAS subscales, and for each PPI factor, analyses testing the homogeneity of effect size were conducted. Because of the large number of analyses conducted, alpha was set at .01. Across the 53 tests, only eight failed to reach statistical significance; effect sizes were homogeneous for four PPI FD relations (i.e., Aggression, FFM Neuroticism, FFM Openness, and Empathy) and for four PPI ScI relations (i.e., mood, MPQ Positive Emotionality, sensation seeking, and empathy). When heterogeneity was present, moderator analyses were undertaken. Because not all moderators are present for each study and not all moderators show sufficient variability for each set of effect sizes, moderators were examined individually using weighted regression analyses; alpha was set at .001. Table 3 provides the results of these analyses. A few findings were quite consistent across PPI factors. Convergence with other psychopathy indices was higher in older, forensic samples with more women using a self-report inventory. For both FD and ScI, relations with internalizing dimensions were stronger (i.e., more negative for FD and more positive for $\mathrm{ScI}$ ) for older samples with more males and more nonwhite participants.

There was also consistent evidence for differences in the size of relations for FD and ScI as a function of which PPI assessment was used; across 45 outcomes, PPI version acted as a moderator in 27 of them. For example, the short form of the PPI showed smaller convergent correlations with other psychopathy assessments for both FD and ScI. Estimated PPI served as a moderator in 18 instances, whereas the original PPI did so in 16 instances. Studies using estimated PPI scores produced greater divergence between the PPI factors in relation to one another, whereas studies using the original PPI found higher correlations between PPI factors. The two versions also operated in opposite directions in relation to internalizing outcomes and NPD; studies using the original PPI found more negative relations with PPI FD and these outcomes but more positive relations for PPI ScI. The opposite was observed for studies using estimated PPI scores which found more positive relations for PPI FD and more negative ones for PPI ScI.

\section{Discussion}

The PPI has rapidly become one of the most commonly used self-report measures of psychopathy in both institutionalized (e.g., Berardino, Meloy, Sherman, \& Jacobs, 2005; Patrick et al., 2006) and noninstitutionalized samples (e.g., Derefinko \& Lynam, 2006; Sellbom \& Verona, 2007). As noted earlier, some researchers have even referred to the PPI as "the gold standard self-report psychopathy measure" (Witt, Donnellan, \& Blonigen, 2009, p. 1007). Despite the significant enthusiasm for the scale, concerns have been raised about the validity of the Fearless Dominance factor (e.g., Gaughan et al., 2009; Miller, Gaughan, \& Pryor, 2008). In order to adjudicate between the claims of the enthusiasts and

\footnotetext{
${ }^{3}$ This analysis provides information only on potential additive effects in which each PPI factor provides additional prediction (i.e., larger effect sizes) when combined with the other. It does not say anything about potential interactive effects in which one factor would exhibit increased predictive power only at certain levels of the other factor. We were unable to identify articles in which PPI FD and PPI ScI were allowed to interact in their prediction of outcomes.
} 
Table 3

Results of Moderator Analyses

\begin{tabular}{|c|c|c|c|c|c|c|c|c|c|c|}
\hline & $\%$ Male & $\%$ White & Age & Prison & PCL & DSM & PPI & PPI-R & PPI-SF & est. PPI \\
\hline \multicolumn{11}{|c|}{ Moderator results for PPI factor 1} \\
\hline PPI F2 & -.002 & ns & -.014 & -.218 & - & - & ns & .269 & -.096 & -.136 \\
\hline F1 psych. & -.002 & ns & -.007 & -.133 & -.127 & - & ns & ns & -.118 & ns \\
\hline F2 psych. & -.002 & ns & -.013 & -.145 & -.114 & - & ns & ns & ns & ns \\
\hline Total psych. & -.002 & ns & -.011 & -.144 & -.128 & - & ns & ns & ns & ns \\
\hline Internalizing & -.003 & .005 & -.011 & ns & - & - & -.217 & -.287 & - & .401 \\
\hline Anxiety & $\mathrm{ns}$ & .005 & -.014 & ns & - & - & ns & - & - & .262 \\
\hline Mood & ns & ns & ns & ns & - & - & -.172 & - & - & .296 \\
\hline Externalizing & .002 & ns & ns & ns & - & - & ns & ns & ns & -.111 \\
\hline ASB & ns & ns & ns & -.196 & - & - & ns & .333 & - & -.224 \\
\hline Subs. Use & ns & ns & -.007 & -.093 & - & - & ns & .091 & 一 & -.106 \\
\hline FFM E & ns & -.004 & $\mathrm{~ns}$ & - & - & - & ns & ns & - & - \\
\hline FFM A & -.003 & ns & ns & - & - & - & ns & ns & - & 一 \\
\hline FFM C & -.005 & -.004 & .049 & - & - & - & -.124 & -.312 & - & - \\
\hline MPQ PEM & ns & ns & ns & - & - & - & $\mathrm{ns}$ & - & - & - \\
\hline MPQ NEM & ns & ns & .011 & - & - & - & .ns & - & ns & ns \\
\hline MPQ CON & ns & ns & .012 & - & - & - & .150 & - & - & - \\
\hline Impulsivity & ns & .005 & -.019 & -.182 & - & - & ns & ns & - & ns \\
\hline Sens. Seek. & ns & ns & ns & ns & - & - & - & .266 & - & -.194 \\
\hline BIS & ns & ns & .012 & ns & - & - & ns & $\mathrm{ns}$ & - & - \\
\hline BAS & ns & ns & ns & ns & - & - & -.163 & ns & - & - \\
\hline APD & ns & -.003 & -.011 & -.180 & - & ns & .185 & - & ns & -.265 \\
\hline NPD & ns & .013 & -.020 & -.230 & - & -.600 & -.148 & - & - & .167 \\
\hline BPD & .004 & -.006 & ns & - & - & - & $\mathrm{ns}$ & - & - & .129 \\
\hline \multicolumn{11}{|c|}{ Moderator results for PPI factor 2} \\
\hline F1 psych. & -.004 & .005 & -.019 & -.131 & -.193 & - & -.135 & .172 & -.158 & .133 \\
\hline F2 psych. & -.003 & ns & -.015 & -.175 & -.276 & - & ns & .203 & -.140 & ns \\
\hline Total psych. & -.005 & .006 & -.028 & -.243 & -.358 & - & -.128 & .216 & -.186 & .086 \\
\hline Internalizing & .005 & -.006 & .015 & .315 & - & - & .324 & - & - & -.418 \\
\hline Anxiety & .003 & -.008 & .013 & ns & - & - & .101 & - & - & -.349 \\
\hline Externalizing & .003 & -.003 & .019 & .331 & - & - & .390 & -.157 & -.259 & -.178 \\
\hline ASB & ns & ns & ns & ns & - & - & ns & ns & ns & ns \\
\hline Aggression & ns & ns & ns & ns & - & - & ns & ns & ns & ns \\
\hline Subs. Use & ns & .002 & ns & ns & - & - & ns & ns & - & ns \\
\hline FFM N & ns & ns & ns & - & - & - & ns & ns & - & - \\
\hline FFM E & ns & -.005 & ns & - & - & - & ns & ns & - & - \\
\hline FFM O & .003 & .004 & ns & - & - & - & -.127 & .283 & - & - \\
\hline FFM A & ns & -.008 & ns & - & - & - & -.125 & ns & - & - \\
\hline FFM C & ns & -.010 & ns & - & - & - & ns & -.239 & - & - \\
\hline MPQ NEM & .003 & ns & .013 & - & - & - & ns & ns & - & -.230 \\
\hline MPQ CON & ns & ns & ns & - & - & - & .213 & - & - & - \\
\hline Impulsivity & ns & ns & - & - & - & - & ns & ns & - & - \\
\hline BIS & ns & ns & .013 & ns & - & - & ns & ns & - & - \\
\hline BAS & ns & .013 & ns & ns & - & - & ns & .364 & - & - \\
\hline APD & ns & ns & -.009 & ns & - & $\mathrm{ns}$ & ns & - & - & - \\
\hline NPD & ns & ns & ns & ns & - & .510 & .290 & - & - & -.355 \\
\hline BPD & .004 & -.004 & ns & ns & - & - & ns & - & - & - \\
\hline
\end{tabular}

Note. $\mathrm{ASB}=$ antisocial behavior; Subs. Use $=$ substance use; FFM N = FFM neuroticism; FFM E $=$ FFM extraversion; FFM O = FFM openness to experience; FFM A = FFM agreeableness; FFM C = FFM conscientiousness; MPQ PEM = MPQ positive emotionality; MPQ NEM = MPQ negative emotionality; MPQ CON = MPQ constraint; Sens. Seek. = sensation seeking; BIS = behavioral inhibition system; BAS = behavioral activation system; RR = reward responsiveness; $\mathrm{APD}=$ antisocial personality disorder; NPD $=$ narcissism/narcissistic personality disorder; $\mathrm{BPD}=$ borderline personality disorder. Dashes indicate that there was insufficient variability to examine moderators in these cases. Variables not appearing in the table were not significantly heterogeneous in their effect sizes and thus moderators were not examined. 
the critics, we conducted a meta-analysis of the PPI scales and their relations with core constructs from psychopathy's nomological network. Our results provide compelling support for the validity of the PPI total score as an overall index of psychopathy. However, the two factors, FD and ScI are distinct as they are uncorrelated with one another (i.e., mean $r=.05$ ) and manifest divergent correlational profiles. We believe the evidence for the construct validity of the Self-centered Impulsivity factor is strong but that support is weaker for the validity of the Fearless Dominance factor.

\section{PPI ScI}

PPI ScI manifested a pattern of effect sizes that is largely consistent with the theoretical and empirical network associated with psychopathy. For instance, PPI ScI manifested substantial positive relations with externalizing behaviors such as aggression, ASB, substance use; personality traits such as interpersonal antagonism, disinhibition/impulsivity; and pathological personality such antisocial personality disorder (APD). PPI ScI demonstrated good convergent validity as indicated by strong correlations with factor 2 and total scores from other psychopathy instruments. In general, PPI ScI appears to be a strong and valid self-report measure of psychopathy demonstrating a pattern of relations with important external criteria that is consistent with the nomological net surrounding psychopathy. From the perspective of the FFM, PPI $\mathrm{ScI}$ assesses the interpersonal antagonism and impulsivity thought central to psychopathy. Similarly, in terms of Patrick's triarchic model, PPI ScI appears to be successful in capturing both the "meanness" and "disinhibition" components of psychopathy.

\section{PPI FD}

Judging by the largest effect sizes (see Table 4 for a summary), PPI FD is most strongly negatively related to the experience of negative emotional states (e.g., neuroticism; negative emotionality; internalizing symptoms; behavioral inhibition) and positively related to positive emotionality, novelty seeking, and a generally outgoing, assertive interpersonal style (e.g., extraversion, positive emotionality; behavioral activation). Unlike most conceptualizations of psychopathy, PPI FD manifests small to null relations with measures of constructs related to interpersonal antagonism, empathy, externalizing behaviors such as aggression, substance use, ASB, and APD. These differences likely explain why PPI FD manifests limited convergent correlations with other psychopathy measures at the factor and total score levels. PPI FD is not closely related to psychopathy as conceptualized by Hare (e.g., 2003) and others (e.g., McCord \& McCord, 1964) or as operationalized by other measures of psychopathy. We return to this issue in greater detail below.

\section{PPI FD and Psychopathy}

The lack of relations manifested by PPI FD with PPI ScI, as well as with constructs that are viewed as important correlates of psychopathy (e.g., ASB, violence, and substance use) raises the question of where PPI FD "fits" within general conceptualizations of psychopathy. As noted in the introduction, there are several possibilities. The current results allow some degree of adjudication among these.

PPI FD and PCL-R factor 1. Initially, it was argued that PPI FD assessed a construct similar to that captured by PCL-R F1 (Benning et al., 2003). The present results do not support this contention. In the present study, PPI FD manifested an average correlation of .23 with other F1 psychopathy indices; this effect size was significantly smaller in studies using the PCL/PCL-R. It is difficult to conceive of PPI FD as an index of PCL F1 when the two instruments share less than $4 \%$ of their variance. These results support the conclusions of Malterer, Lilienfeld, Neumann, and Newman (2010) who indicated that PPI FD and factor 1 from the PCL-R/PCL: SV should not be considered fungible.

Some researchers have attempted to argue for the similarity of PPI FD and PCL-R F1 based on findings that PPI FD is more strongly related to factor 1 than factor 2 scores, whereas the reverse is true for PPI ScI (Benning, Patrick, Blonigen, et al., 2005). Such a condition does hold in the present analyses; PPI FD is more strongly related to other factor 1 scales than to other factor 2 scales (i.e., .23 vs. .07) and the reverse is true for PPI ScI (.38 vs. .53), but PPI ScI is more strongly related than PPI FD to both F1 (.38 vs. .23) and F2 (.53 vs. .07) scales.

The argument for similarity between PPI FD 
Table 4

Summary of Meta-Analytically Derived Effect Sizes for PPI Factors 1 and 2

\begin{tabular}{|c|c|c|}
\hline Mean ES & $\begin{array}{c}\text { PPI F1 } \\
\text { (Fearless dominance) }\end{array}$ & $\begin{array}{c}\text { PPI F2 } \\
\text { (Self-centered impulsivity) }\end{array}$ \\
\hline \multirow[t]{6}{*}{$>.50$} & Behavioral inhibition scale $(-)$ & Factor 2 psychopathy $(+)$ \\
\hline & FFM neuroticism $(-)$ & MPQ constraint $(-)$ \\
\hline & FFM extraversion $(+)$ & Impulsivity $(+)$ \\
\hline & & Antisocial PD $(+)$ \\
\hline & & Psychopathy total $(+)$ \\
\hline & & FFM conscientiousness $(-)$ \\
\hline \multirow{5}{*}{.40 to .49} & Sensation seeking $(+)$ & FFM agreeableness $(-)$ \\
\hline & MPQ Positive emotionality (+) & Borderline PD $(+)$ \\
\hline & BAS: Fun seeking $(+)$ & Externalizing $(+)$ \\
\hline & & Sensation seeking $(+)$ \\
\hline & & Aggression $(+)$ \\
\hline \multirow[t]{5}{*}{.30 to .39} & Narcissism/narcissistic PD $(+)$ & Factor 1 psychopathy $(+)$ \\
\hline & BAS total $(+)$ & Antisocial behavior $(+)$ \\
\hline & Anxiety $(-)$ & MPQ Negative emotionality (+) \\
\hline & Internalizing $(-)$ & BAS: fun seeking $(+)$ \\
\hline & MPQ negative emotionality $(-)$ & FFM neuroticism $(+)$ \\
\hline \multirow[t]{6}{*}{.20 to .29} & BAS: Drive $(+)$ & Internalizing $(+)$ \\
\hline & FFM openness $(+)$ & Substance use $(+)$ \\
\hline & Factor 1 psychopathy $(+)$ & Anxiety (+) \\
\hline & Mood $(-)$ & Empathy $(-)$ \\
\hline & & Narcissism/narcissistic PD $(+)$ \\
\hline & & Mood $(+)$ \\
\hline \multirow[t]{5}{*}{.10 to .19} & MPQ constraint $(-)$ & BAS total $(+)$ \\
\hline & Borderline PD (-) & MPQ positive emotionality (-) \\
\hline & Psychopathy total $(+)$ & Behavioral inhibition scale $(-)$ \\
\hline & Antisocial behavior $(+)$ & FFM extraversion $(-)$ \\
\hline & FFM agreeableness $(-)$ & \\
\hline \multirow[t]{9}{*}{$<.10$} & Empathy $(-)$ & BAS: drive $(+)$ \\
\hline & BAS: reward responsiveness $(+)$ & FFM openness $(+)$ \\
\hline & Factor 2 psychopathy $(+)$ & BAS: reward responsiveness $(+)$ \\
\hline & Antisocial PD $(+)$ & \\
\hline & Substance use $(+)$ & \\
\hline & Externalizing $(+)$ & \\
\hline & Aggression $(-)$ & \\
\hline & Impulsivity $(-)$ & \\
\hline & FFM conscientiousness $(-)$ & \\
\hline
\end{tabular}

Note. $\quad \mathrm{ES}=$ effect size; FFM = Five Factor Model; MPQ $=$ Multidimensional Personality Questionnaire; BAS = Behavioral Activation Scale; $\mathrm{PD}=$ personality disorder.

and PCL-R F1 has not always been based on the convergence between the two scales but on the putative similarity of correlations with external criteria. For example, Benning and colleagues (2003) argued that both the PPI and PCL-R factor 1 scores manifest "negligible" relations with substance use, small correlations with $\mathrm{ASB}$, and produce a similar pattern of correlations with general personality traits. However, the PCL-R factor 1 and PPI FD correlates are not as similar as suggested. The PCL-R F1 correlates described above were often based on partial correlations in which PCL-R F2 scores were partialed from F1 scores. Partialing changes variables in ways that are difficult to discern. In their examination of the "perils of partialing," Lynam, Hoyle, \& Newman (2006) reported very little correspondence between the correlational profiles of the partialed and unpartialed PCL-R F1 scores. For example, in one of the studies cited by Benning and colleagues as being supportive of "low correlations" between the PCL-R F F1 and ASB (i.e., Verona et al., 2001), the zero-order correlation between PCL-R F1 and ASB was significant and of moderate size (i.e., $r=.35$ ); the relation was 
only "low" when reported as a partial correlation (e.g., $r=-.01$ ). In fact, PCL-R F1 scores tend to manifest significant correlations with ASB and APD at the bivariate level (see Hare, 2003, for a review).

This problem also exists in the correlations with dimensions of general personality. Results from the present study indicate that PPI FD is negatively correlated with FFM Neuroticism (strongly) and MPQ Negative Emotionality (moderately); positively correlated with FFM Extraversion (strongly) and MPQ Positive Emotionality (moderately); and mostly uncorrelated with FFM Agreeableness. At the bivariate level, PCL-R F1 scores manifest null to weak correlations with traits related to negative and positive emotionality, and a moderate negative correlation with Agreeableness. Although the relations change somewhat when PCL-R F2 is partialed from PCL-R F1, the relations for negative and positive emotionality are orders of magnitude smaller than for PPI FD. In sum, it seems unlikely that PPI FD offers a valid selfreport assessment of PCL-R factor 1.

PPI FD and the mask of sanity. More recently, based on the substantial negative correlations between PPI FD and internalizing symptoms and related behaviors (e.g., suicide; Douglas, Lilienfeld, Skeem, Poythress, Edens, \& Patrick, 2008), some have argued that this construct "is reminiscent of Cleckley's depiction of the psychopathic individual as welladjusted in some respects" (Edens, Poythress, Lilienfeld, Patrick, \& Test, 2008, p. 89). Patrick and colleagues (2006) suggested that "PPI-I [FD] assesses, at least in part, the convincing "mask" of sanity that Cleckley regarded as central to psychopathy" (p. 207)." We believe that there are problems with this account as well.

Cleckley (1988) did include several traits in his description of psychopathy that might indicate good adjustment-charm, good intelligence, absence of nervousness, and a relative immunity to suicide. It may be true that these traits are the ones that provide the mask of sanity for the psychopathic individual, but it is certainly true that Cleckley believed severe disturbance lay behind this mask. He wrote that "the psychopath, however perfectly he mimics man theoretically...f fails altogether when he is put into the practice of actual living. His failure is so complete and so dramatic that it is difficult to see how the failure could be achieved by anyone less defective than a downright madman..." (Cleckley, 1988, p. 370). For Cleckley, the seeming adjustment was belied by the gross impairment seen across time in other areas of the psychopathic individual's life and by the other traits that characterize the syndrome: unreliability, untruthfulness, lack of remorse, inadequately motivated ASB, poor judgment, failure to learn from experience, pathological egocentricity, incapacity for love, interpersonal unresponsiveness, and failure to follow any life plan. The positive traits noted above become important only in the face of the broader dysfunction identified by Cleckley and captured by PPI ScI and more traditional psychopathy assessments. In the absence of the more traditional psychopathy traits and related impairment, traits related to charm, intelligence, emotionally stability, and a relative immunity to suicide are not serving as masks of sanity but rather as markers of healthy adjustment.

The problem for PPI FD is that it captures primarily adaptive functioning - there is no evidence that the traits associated with PPI FD are masking underlying personality pathology or dysfunction, given that it is uncorrelated with the more maladaptive aspects of psychopathy (i.e., PPI ScI). In this regard, it is informative to examine the potential diagnostic confusions that Cleckley anticipated. He devoted a large portion his book to distinguishing his conception of psychopathy from 11 other conditions that might be confused with psychopathy: 1) the psychotic, 2) patients with deviations recognized as similar to the psychoses but regarded as incomplete or less severe reactions, 3) the psychoneurotic, 4) the mental defective, 5) the ordinary criminal, 6) other character and behavior disorders, including delinquency, 7) specific homosexuality and other consistent sexual deviation, 8) the erratic man of genius, 9) the injudicious hedonist and some other drinkers, 10) the clinical alcoholic, and 11) the malingerer. It did not seem to occur to Cleckley that the psychopath might be mistaken for a successful, welladjusted, mentally healthy individual. It appears to be this differential diagnosis that is most difficult for the conception inherent in the PPI FD. 
PPI FD and "psychopathic boldness." Most recently, Patrick, Fowles, and Krueger (2009) put forth a triarchic model of psychopathy in which they argue that there are three separable components of psychopathy: meanness, boldness, and disinhibition. Boldness refers to "a capacity to remain calm and focused in situations involving pressure or threat, an ability to recover quickly from stressful events, high self-assurance and social efficacy, and a tolerance for unfamiliarity and danger" (Patrick et al., 2009, p. 926). They further argue that PPI-FD "appears to reflect a purer, more benign expression of underlying temperamental fearlessness (termed "boldness") than Factor 1 of the PCL-R .... the construct of boldness indexed by PPI-I is likely to be particularly relevant to the conceptualization of and measurement of psychopathy in noncriminal samples, including identification of individuals with psychopathic tendencies who ascend to positions of leadership and influence in society" (p. 925).

We believe there are issues with this view of PPI Fearless Dominance as well. First, PPI FD is not simply benign, but rather appears salutary, generally protecting individuals from psychopathology (i.e., it is negatively correlated with internalizing symptoms/disorders and generally manifests null to small correlations with externalizing symptoms/disorders). Second, it is not clear why even a benign, let alone salutary, expression of boldness should be considered part of psychopathy. We agree with Hare \& Neumann (2008, p. 227) who, when addressing the possible omission of positive adjustment items in the PCL-R (which are found in PPI FD), suggested that "psychiatric disorders, including personality disorders, typically are defined in terms of maladjustment, not in terms of positive adjustment (Livesley, 2007)" and it is not clear what advantage these traits confer in the assessment of psychopathy. Although one might argue that these traits might be indicative of "successful psychopathy," this would not be entirely consistent with relevant empirical studies. Mullins-Sweatt, Glover, Derefinko, Miller, and Widiger (2010) generated FFM ratings of successful psychopaths as rated by psychologists and lawyers and found that the primary difference between criminal psychopaths and successful psychopaths was found in the domain and facets of Conscientiousness (i.e., higher scores in successful psychopaths). Un- like individuals with high scores on PPI FD, successful psychopaths were rated as being substantially antagonistic (i.e., low on facets such as straightforwardness, trust, modesty, and tendermindedness). In sum, successful psychopaths appear to be much "meaner" than individuals characterized by high scores on PPI FD.

PPI FD and low fear. Up to this point, PPI FD does not fit well within the traditional conceptions of Hare and Cleckley. It is possible, however, that PPI FD may be indexing, as suggested by Edens et al. (2008), a more specific alternative conception-Lykken's primary psychopathy. In this theory, Lykken suggests that the primary psychopath is deficient in his or her anxiety or fear responsiveness, making successful socialization, which depends on fearful inhibition, much more difficult but not impossible. In fact, if socialization is successful despite the low fear of the child, Lykken (1995) suggests a hero will be born: "the hero and the psychopath may be twigs on the same genetic branch" (p. 118). Although PPI FD is negatively related to anxiety as would be predicted, its relations to other variables would seem to weaken its case as an indicator of primary psychopathy.

First, whereas Lykken (1995) predicted "an attenuated experience, not of all emotional states, but specifically of anxiety or fear" (p. 118), PPI FD is associated with the attenuated experience of all aspects of negative emotionality including anxiety, anger, sadness, and depression. Second, at several points in his writings on psychopathy, Lykken made an explicit distinction between anxiety assessed via measures of neuroticism and fear assessed via his own activities preference questionnaire (APQ; Lykken, 1957). Given that the APQ served as the basis for the Harm Avoidance subscale of the MPQ, one would expect large negative relations between PPI FD and indices of Constraint - the higher-order factor to which harm avoidance contributes. Although a mean weighted effect size of -.17 was observed between PPI FD and MPQ constraint, this relation is much smaller than the relations observed between PPI ScI and constraint (i.e., - .55) and between PPI FD and indicators of neuroticism. To the degree that Lykken was correct in drawing a distinction between general neuroticism and fear, PPI FD seems a much better indicator of the former than the latter. Third, Lykken 
believed that low fear would manifest as primary psychopathy, a particular manifestation of antisocial personality, under most child rearing circumstances: "the low fear hypothesis does not claim that persons with the genetic talent for psychopathy must fail to become adequately socialized but merely that they are more likely to fail, given typical parenting (Lykken, 1995, p. 154). This theory suggests that there should be a main effect of fearlessness on externalizing problems-an effect not observed for PPI FD. Finally, the general lack of relations between PPI FD and other indices of psychopathy including PPI ScI runs counter to predictions by Lykken who believed that "all components of the syndrome outlined in Cleckley's 16 criteria might be expected to be found in a normal but relatively fearless child who has been subjected to the typical parenting methods that rely primarily on punishment for the development of conscience and the inhibition of antisocial behavior" (p. 135).

PPI FD as stable extraversion (Eysenck \& Rachman, 1965). Finally, on the basis of the present meta-analytic results, we offer an alternative interpretation of PPI FD, which is that this factor assesses stable extraversion, which may be an associated feature or a diagnostic specifier for psychopathy. The feature itself is not essential and, in the absence of evidence of impairment, maladaptivity, or high scores on traits related to meanness and disinhibition, does not itself index psychopathy. The present meta-analysis indicates that high scorers on PPI FD are relatively immune to both internalizing and externalizing forms of psychopathology. From a personality perspective, high scorers are emotionally stable, calm, even-tempered, and relaxed (i.e., low in neuroticism). They are also sociable, warm, cheerful, optimistic, dominant, and energetic (i.e., high in extraversion). These two traits by themselves-low neuroticism and high extraversion - are associated with adaptive functioning across a host of life domains (Few et al., 2010; Hopwood et al., 2009). In fact, the trait correlates of PPI FD are more consistent with those manifested by trait happiness (Francis, Brown, Lester, \& Philipchalk, 1998) and self-esteem (Campbell \& Miller, in press) than they are with traditional conceptions of psychopathy. Moreover, individuals high on fearless dominance are also somewhat elevated on Openness to Experience, a dimension that in- cludes imagination, attentiveness to inner experience, preference for variety, and intellectual curiosity. Without co-occurring elevations on PPI ScI, we believe that PPI FD is largely assessing psychological adjustment and adaptive functioning in a manner that is distinct from how the psychopathy construct has been conceived of and studied over the past 30 years.

Some might question this interpretation given that PPI FD is correlated with scales measuring narcissism/NPD, behavioral inhibition, and sensation seeking. These correlations are to be expected, however, given that these three constructs are also composed, in part, by high scores on extraversion and lower scores on neuroticism. With regard to narcissism/NPD, the current data suggest that PPI FD is only correlated with trait narcissism as measured by the Narcissistic Personality Inventory (NPI; Raskin \& Terry, 1988; ES $[\mathrm{k}=6]=.52$ ) but not measures of DSM-IV Narcissistic Personality Disorder $(\mathrm{ES}[\mathrm{k}=2]=.001)$. The NPI has been the subject of intense criticism for measuring an adaptive, nonpathological variant of narcissism (e.g., Brown, Budzek, \& Tamborski, 2009; Rosenthal \& Hooley, 2010). For example, Pincus and Lukowitsky (2010) suggest that the "NPI does not assess subclinical narcissism reflecting a continuum of functioning, but rather predominantly assesses nondistressed adaptive expressions of the construct" (p. 425). Others have countered these claims (e.g., Miller, Maples, \& Campbell, in press) by pointing to the robust relation that NPI bears to the FFM domain of Agreeableness (i.e., meta-analytic $\mathrm{ES}=-.39$, see Campbell \& Miller, in press); such a counterclaim, however, is not available to proponents of PPI FD as it manifests a much smaller correlation with Agreeableness (i.e., meta-analytic $\mathrm{ES}=-.10$ ).

As noted above, the strong correlation with behavioral inhibition (negatively) and sensation seeking (positively) with PPI-FD are also to be expected given their correlations with measures of extraversion/positive emotionality and neuroticism/negative emotionality. In fact, Poythress et al. (2008, p. 272), after meta-analytically examining the correlations between the BIS and measures of neuroticism, anxiety, and negative affect, concluded that the BIS "is largely a measure of NE [Negative Emotionality]." In fact, based on these results, the authors called 
for a moratorium on the use of the BIS to test Lykken's low fear or "weak BIS" hypothesis.

\section{Limitations and Conclusions}

There are several limitations to the current study. Although the number of effect sizes was relatively large for some outcomes (e.g., other psychopathy scales, externalizing problems), the number was small for other outcomes (e.g., most of the individual traits and personality disorders). Thus, the mean effect sizes presented here differ somewhat in their precision depending on the specific outcome- a fact reflected in the differently sized confidence intervals. Additionally, outcomes that had fewer than six effect sizes were not included; these omitted outcomes included at least one construct believed to be important in some conceptions of psychopathy-fear-potentiated startle. It is important to note, however, that the presumed centrality of a construct is no guarantee of its observed effect size. For example, in the three published studies that address the relation between fear-potentiated startle and PPI scores (i.e., Anderson, Wan, Young, \& Stanford, 2011; Benning, Patrick, \& Iacono, 2005; Vaidyanathan, Patrick, \& Bernat, 2009), the mean weighted effect sizes for the PPI factors are not statistically significantly different from zero; the mean weighted ES for PPI FD is -.047 with a $95 \%$ confidence interval ranging from -.171 to .079 , whereas the mean weighted effect size for PPI ScI is .072 with a $95 \%$ confidence interval ranging from -.084 to .224 . In addition, driven by the available literature, we have examined the two PPI factors in the context of the nomological network surrounding Hare's operationalization of psychopathy.

Finally, we chose to restrict our analysis to published studies, rather than including unpublished data and dissertations. This decision may raise concern about what might be hiding in the file drawers of psychopathy researchers. The file drawer concern is based on a bias against publishing statistically nonsignificant findings and is typically believed to result in an overestimate of the true population effect size. We believe the present results themselves provide a counter to such a concern. The small mean effect sizes observed for PPI FD across several central psychopathy outcomes (e.g., empathy, APD, substance use, aggression, and impulsiv- ity) argues against the typical publication bias. Moreover, although the two factors PPI factors bear different relations to almost every outcome, the range of effect sizes for PPI FD and PPI ScI are generally similar. A strange bias would seem necessary to produce such findings. Thus, despite the potential limitations, the current results provide a relatively comprehensive and robust picture of the nature of the relations between the PPI factors and many central correlates found in psychopathy's empirical literature.

Ultimately, we believe the results provide support for the use of the PPI ScI as it demonstrates strong convergent correlations with other established psychopathy measures and an expected pattern of correlations with important constructs such as externalizing behaviors, general personality traits (e.g., interpersonal antagonism, empathy, impulsivity), and pathological personality traits and disorders (i.e., APD). It is our opinion that the same cannot be stated for PPI FD. We believe individuals interested in the assessment and study of psychopathy should cautious in concluding that individuals with high scores on PPI FD alone are psychopathic; instead, these individuals may be among the more psychologically healthy individuals in a given population. Overall, we find little evidence to suggest that fearless dominance, as assessed by PPI-FD, can be considered an equally central component of psychopathy as "meanness" (i.e., antagonism) and "disinhibition" (i.e., low conscientiousness/constraint). It may be that PPI FD is related to psychopathy, as it is currently measured, only when paired with high levels of antagonism and/or impulsivity (see Lilienfeld \& Fowler, 2006, for a discussion of configural models of psychopathy, particularly as these models pertain to the PPI). However, the same might not be said for meanness or disinhibition - that is, we believe individuals can be characterized as psychopathic with high levels of either (or both) of those traits, irrespective of levels of fearless dominance, suggesting that FD is less central to the description of psychopathy. It is important to note, however, that proponents of PPI FD have not, to our awareness, characterized PPI-FD in this way (i.e., that it is relevant to psychopathy only in the presence of either or both meanness and/or disinihibition). If this conceptualization is in fact consistent with either the dual process 
model of psychopathy (Fowles \& Dindo, 2009) or the triarchic model (Patrick et al., 2009), it would benefit the field for this to be stated much more explicitly.

\section{References}

References marked with an asterisk indicate studies included in the meta-analysis.

American Psychiatric Association. (2000). Diagnostic and statistical manual of mental disorders (4th ed., text revision). Washington, DC: Author.

Anderson, N. E., Wan, L., Young, K. A., \& Stanford, M. (2011). Psychopathic traits predict startle habituation but not modulation in an emotional faces task. Personality and Individual Differences, 50, 712-716.

*Baskin-Sommers, A. R., Zeier, J. D., \& Newman, J. P. (2009). Self-reported attentional control differentiates the major factors of psychopathy. Personality and Individual Differences, 47, 626-630.

*Benning, S. D., Patrick, C. J., Blonigen, D. M., Hicks, B. M., \& Iacono, W. G. (2005). Estimating facets of psychopathy from normal personality traits: A step toward community epidemiological investigations. Assessment, 12, 3-18.

*Benning, S. D., Patrick, C. J., Hicks, B. M., Blonigen, D. M., \& Krueger, R. F. (2003). Factor structure of the Psychopathic Personality Inventory: Validity and implications for clinical assessment. Psychological Assessment, 15, 340-350.

Benning, S. D., Patrick, C. J., \& Iacono, W. G. (2005). Psychopathy, startle blink modulation, and electrodermal reactivity in twin men. Psychophysiology, 42, 753-762.

*Benning, S. D., Patrick, C. J., Salekin, R. T., \& Leistico, A.-M. (2005). Convergent and discriminant validity of psychopathy factors assessed via self-report: A comparison of three instruments. Assessment, 12, 270-289.

*Berardino, S. D., Meloy, J. D., Sherman, M., \& Jacobs, D. (2005). Validation of the Psychopathic Personality Inventory on a female inmate sample. Behavioral Sciences and the Law, 23, 819-836.

Blackburn, R., \& Coid, J. (1998). Psychopathy and the dimensions of personality disorder in violent offenders. Personality and Individual Differences, 25, 129-145.

*Blonigen, D. M., Patrick, C. J., Douglas, K. S., Poythress, N. G., Skeem, J. L., Lilienfeld, S. O., . . Krueger, R. F. (2010). Multimethod assessment of psychopathy in relation to factors of internalizing and externalizing from the Personality Assessment Inventory: The impact of method variance and suppressor effects. Psychological Assessment, 22, 96-107.
Brown, R. P., Budzek, K., \& Tamborski, M. (2009). On the meaning and measure of narcissism. Personality and Social Psychology Bulletin, 35, 951964.

Caldwell, M. F., Ziemke, M. H., \& Vitacco, M. J. (2008). An examination of the Sex Offender Registration and Notification Act as applied to juveniles: Evaluating the ability to predict sexual recidivism. Psychology, Public Policy, and Law, 14, 89-11.

Campbell, W. K., \& Miller, J. D. (in press). Narcissistic personality disorder (NPD) and the Five Factor Model: Delineating NPD, grandiose narcissism, and vulnerable narcissism. In P. T. Costa \& T. A. Widiger (Eds.), Personality disorders and the Five Factor Model of Personality (3rd ed.). Washington, DC: APA.

*Chapman, A. L., Gremore, T. M., \& Farmer, R. F. (2003). Psychometric analysis of the Psychopathic Personality Inventory (PPI) with female inmates. Journal of Personality Assessment, 80, 164-172.

Claes, L., Vertommen, S., Soenens, B., Eyskens, A., et al. (2009). Validation of the Psychopathic Personality Inventory among psychiatric inpatients: sociodemographic, cognitive and personality correlates. Journal of Personality Disorders, 23, 477493.

Cleckley, H. (1941/1988). The mask of sanity. St. Louis, MO: Mosby.

Cooke, D. J., \& Michie, C. (2001). Refining the construct of psychopath: Towards a hierarchical model. Psychological Assessment, 13, 171-188.

Cronbach, L. J., \& Meehl, P. E. (1955). Construct validity in psychological tests. Psychological Bulletin, 52, 281-302.

*Del Gaizo, A. L., \& Falkenbach, D. M. (2008). Primary and secondary psychopathic traits and their relationship to perception and experience of emotion. Personality and Individual Differences, 45, 206-212.

*Denson, T. F., White, A. J., \& Warburton, W. A. (2009). Trait displaced aggression and psychopathy differentially moderate the effects of acute alcohol intoxication and rumination on triggered displaced aggression. Journal of Research in Personality, 43, 673-681.

*Derefinko, K. J., \& Lynam, D. R. (2006). Convergence and divergence among self-report psychopathy measures: A personality-based approach. Journal of Personality Disorders, 20, 261-280.

Douglas, K. S., Lilienfeld, S. O., Skeem, J. L., Poythress, N. G., Edens, J. F., \& Patrick, C. J. (2008). Relation of antisocial and psychopathic traits to suicide-related behavior among offenders. Law and Human Behavior, 32, 511-525.

Edens, J. F., \& McDermott, B. E. (2010). Examining the construct validity of the Psychopathic Personality Inventory-Revised: Preferential correlates of 
fearless dominance and self-centered impulsivity. Psychological Assessment, 22, 32-42.

*Edens, J. F., Poythress, N. G., Lilienfeld, S. O., \& Patrick, C. J. (2008). A prospective comparison of two measures of psychopathy in the prediction of institutional misconduct. Behavioral Sciences and the Law, 26, 529-541.

*Edens, J. F., Poythress, N. G., Lilienfeld, S. O., Patrick, C. J., \& Test, A. (2008). Further evidence of the divergent correlates of the Psychopathic Personality Inventory factors: Prediction of institutional misconduct among male prisoners. Psychological Assessment, 20, 86-91.

*Eisenbarth, H., Alpers, G. W., Conzelmann, A., Jacob, C. P., Weyers, P., \& Pauli, P. (2008). Psychopathic traits in adult ADHD patients. Personality and Individual Differences, 45, 468-472.

Eysenck, H. J., \& Rachman, S. (1965). The causes and cures of neurosis: An introduction to modern behaviour therapy based on learning theory and the principles of conditioning. San Diego, CA: RR Knapp.

*Falkenbach, D., Poythress, N. G., Falki, M., \& Manchak, S. (2007). Reliability and validity of two self-report measures of psychopathy. Assessment, 14, 341-350.

Few, L. R., Miller, J. D., Morse, J. Q., Yaggi, K. E., Reynolds, S. K., \& Pilkonis, P. A. (2010). Examining the reliability and validity of clinician ratings on the Five-Factor Model score sheet. Assessment, 17, 440-453.

*Fowler, K. A., \& Lilienfeld, S. O. (2007). The psychopathy q-sort: Construct validity evidence in a nonclinical sample. Assessment, 14, 75-79.

Fowles, D. C., \& Dindo, L. (2006). A dual deficit model of psychopathy. In C. J. Patrick (Ed.), Handbook of psychopathy (pp. 14-34). New York: Guilford Press.

Francis, L. J., Brown, L. B., Lester, D., \& Philipchalk, R. (1998). Happiness as stable extraversion: A cross-cultural examination of the reliability and validity of the Oxford Happiness Inventory among students in the U. K., USA, Australia, and Canada. Personality and Individual Differences, 24, 167171.

Frick, P. J., \& Hare, R. D. (2001). The Antisocial Process Screening Device (APSD). Toronto: Multi-Health Systems.

Fulton, J. J., Marcus, D. K., \& Payne, K. T. (2010). Psychopathic personality traits and risky sexual behavior in college students. Personality and Individual Differences, 49, 29-33.

*Gaughan, E. T., Miller, J. D., Pryor, L. R., \& Lynam, D. R. (2009). Comparing two alternative models of general personality in the assessment of psychopathy: A test of the NEO PI-R and the MPQ. Journal of Personality, 77, 965-996.
Gretton, H. M., Hare, R. D., \& Catchpole, R. E. (2004). Psychopathy and offending from adolescence to adulthood: A ten year follow-up. Journal of Clinical and Consulting Psychology, 72, 636-645.

Gustavson, C., Stahlberg, O., Sjodin, A., Forsman, A., Nilsson, T., \& Anckarsater, H. (2007). Age at onset of substance abuse: A crucial covariate of psychopathic traits and aggression in adult offenders. Psychiatry Research, 153, 195-198.

Hare, R. D. (1985). A comparison of procedures for the assessment of psychopathy. Journal of Consulting and Clinical Psychology, 53, 7-16.

Hare, R. D. (1991). Manual for the Psychopathy Checklist-Revised. Toronto: Multi-Health Systems.

Hare, R. D. (2003). The Hare Psychopathy ChecklistRevised (2nd Ed.). Toronto: Multi-Health Systems.

Hare, R. D., \& Neumann, C. S. (2008). Psychopathy as a clinical and empirical construct. Annual Review of Clinical Psychology, 4, 217-246.

Harpur, T. J., Hare, R. D., \& Hakstian, A. R. Hakstian (1989). Two-factor conceptualization of psychopathy: Construct validity and assessment implications. Psychological Assessment: A Journal of Consulting and Clinical Psychology, 1, 6-17.

Hedges, L. V., \& Olkin, I. (1985). Statistical methods for meta-analysis. Orlando, FL: Academic Press.

*Helfritz, L. E., \& Stanford, M. S. (2006). Personality and psychopathology in an impulsive aggressive college sample. Aggressive Behavior, 32, 28-37.

Hemphill, J. F., Hare, R. D., \& Wong, S. (1998). Psychopathy and recidivism: A review. Legal and Criminological Psychology, 3, 139-170.

Hildebrand, M., \& de Ruiter, C. (2004). PCL-R psychopathy and its relation to $D S M-I V$ Axis I and II disorders in a sample of male forensic psychiatric patients in the Netherlands. International Journal of Law and Psychiatry, 27, 233-248.

Hopwood, C. J., Morey, L. C., Ansell, E. B., Grilo, C. M., Sanislow, C. A., McGlashan, T. H., .. . Skodol, A. E. (2009). The convergent and discriminant validity of the five-factor traits: Current and prospective social, work, and recreational dysfunction. Journal of Personality Disorders, 23, 466-447.

*Howard, M. O., Balster, R. L., Cottler, L. B., Wu, L-T., \& Vaughan, M. G. (2008). Inhalant use among incarcerated adolescents in the United States: Prevalence, characteristics, and correlates of use. Drug and Alcohol Dependence, 93, 197-209.

*Justus, A. N., \& Finn, P. R. (2007). Startle modulation in non-incarcerated men and women with psychopathic traits. Personality and Individual Differences, 43, 2057-2071.

Karpman, B. (1941). On the need of separating psychopathy into two distinct clinical types: The symptomatic and the idiopathic. Journal of Criminology and Psychopathology, 3, 112-137. 
Kennealy, P. J., Hicks, B. M., \& Patrick, C. J. (2007). Validity of the factors of the Psychopathy Checklist-Revised in female prisoners. Assessment, 14, 323-340.

*Kruh, I. P., Whittemore, K., Arnaut, G. L. Y., Manley, J., Gage, B., \& Gagliardi, G. J. (2005). The concurrent validity of the Psychopathic Personality Inventory and its relative association with past violence in a sample of insanity acquittees. International Journal of Forensic Mental Health, 4, 135-145.

Levenson, M. R., Kiehl, K. A., \& Fitzpatrick, C. M. (1995). Assessing psychopathic attributes in a noninstitutionalized population. Journal of Personality and Social Psychology, 68, 151-158.

*Lilienfeld, S. O., \& Andrews, B. P. (1996). Development and preliminary validation of a self-report psychopathy measure of psychopathic personality traits in noncriminal populations. Journal of Personality Assessment, 66, 488-524.

Lilienfeld, S. O., Fowler, K. A., (2006). The selfreport assessment of psychopathy: Problems, pitfalls, and promises. In C. J. Patrick (Ed.), Handbook of psychopathy. (pp. 107-132). New York: Guilford Press.

*Lilienfeld, S. O., \& Widows, M. R. (2005). Professional manual for the Psychopathic Personality Inventory-Revised: (PPI-R). Lutz, FL: Psychological Assessment Resources.

Lykken, D. T. (1957). A study of anxiety in the sociopathic personality. Journal of Abnormal and Social Psychology, 55, 6-10.

Lykken, D. T. (1995). The antisocial personalities. Hillsdale, NJ: Erlbaum.

Lynam, D. R., Derefinko, K. J. (2006). Psychopathy and Personality. In C. J. Patrick (Ed.) Handbook of psychopathy. (pp. 133-155). New York: Guilford Press.

* Lynam, D. R., Gaughan, E. T., Miller, J. D., Miller, D. J., Mullins-Sweatt, S., \& Widiger, T. A. (2011). Assessing the basic traits associated with psychopathy: Development and validation of the Elemental Psychopathy Assessment. Psychological Assessment, 23, 108-124.

Lynam, D. R., Hoyle, R. H., \& Newman, J. P. (2006). The perils of partialling: Cautionary tales from aggression and psychopathy. Assessment, 13, 328-341.

Lynam, D. R., \& Widiger, T. A. (2007). Using a general model of personality to identify the basic elements of psychopathy. Journal of Personality Disorders, 21, 160-178.

*Malterer, M. B., Lilienfeld, S. O., Neumann, C. S., \& Newman, J. P. (2010). Concurrent validity of the psychopathic personality inventory with offender and community samples. Assessment, 17, $3-15$.
McCord, W., \& McCord, J. (1964). The psychopath: An essay on the criminal mind. Princeton, NJ: Van Nostrand.

Miller, J. D., Gaughan, E. T., \& Pryor, L. R. (2008). The Levenson Self-Report Psychopathy Scale: An examination of the personality traits and disorders associated with the LSRP factors. Assessment, 15, $450-463$.

Miller, J. D., Lynam, D. R., Widiger, T., \& Leukefeld, C. (2001). Personality disorders as extreme variants of common personality dimensions: Can the Five Factor Model adequately represent psychopathy? Journal of Personality, 69, 253-276.

Miller, J. D., Maples, J., \& Campbell, W. K. (in press). Comparing the construct validity of scales derived from the Narcissistic Personality Inventory: A reply to Rosenthal and Hooley (2010). Journal of Research in Personality.

*Mullins-Nelson, J. L., Salekin, R. T., \& Leistico, A. R. (2006). Psychopathy, empathy, and perspective-taking ability in a community sample: Implications for the successful psychopathy concept. International Journal of Forensic Mental Health, 5, 133-149.

Mullins-Sweatt, S. N., Glover, N. G., Derefinko, K., J., Miller, J. D., \& Widiger, T. A. (2010). The search for the successful psychopath. Journal of Research in Personality, 44, 554-558.

Neumann, C. S., Malterer, M. B., \& Newman, J. P. (2008). Factor structure of the Psychopathic Personality Inventory (PPI): Findings from a large incarcerated sample. Psychological Assessment, 20, 169-174.

*Ostrov, J. M., \& Houston, R. J. (2008). The utility of forms and functions of aggression in emerging adulthood: Association with personality disorder symptomatology. Journal of Youth and Adolescence, 37, 1147-1158.

Patrick, C. J. (2006). Back to the future: Cleckley as a guide to the next generation of psychopathy research. In C. J. Patrick (Ed.), Handbook of Psychopathy (pp. 605-617). New York: Guilford Press.

Patrick, C. J., Bradley, M., \& Lang, P. J. (1993). Emotion in the criminal psychopath: Startle reflex modulation. Journal of Abnormal Psychology, 102, 82-92.

*Patrick, C. J., Edens, J. F., Poythress, N. G., Lilienfeld, S. O., \& Benning, S. D. (2006). Construct validity of the Psychopathic Personality Inventory two-factor model with offenders. Psychological Assessment, 18, 204-208.

Patrick, C. J., Fowles, D. C., \& Krueger, R. F. (2009). Triarchic conceptualization of psychopathy: Developmental origins of disinhibition, boldness, and meanness. Developmental Psychopathology, 21, 913-938. 
Pincus, A. L., \& Lukowitsky, M. R. (2010). Pathological narcissism and narcissistic personality disorders. Annual Review of Psychology, 6, 421-446.

Porter, S., Birt, A. R., \& Boer, D. P. (2001). Investigation of the criminal and conditional release histories of Canadian federal offenders as a function of psychopathy and age. Law and Human Behavior, 25, 647-661.

Poythress, N. G., Edens, J. F., Landfield, K., Lilienfeld, S. O., Skeem, J. L., \& Douglas, K. S. (2008). A critique of Carver and White's (1994) behavioral inhibition scale (BIS) for investigating Lykken's (1995) theory of primary psychopathy. Personality and Individual Differences, 45, 269-275.

*Poythress, N. G., Lilienfeld, S. O., Skeem, J. L., Douglas, K. S., Edens, J. F., Epstein, M., \& Patrick, C. J. (2010). Using the PCL-R to help estimate the validity of two self-report measures of psychopathy with offenders. Assessment, 17, 206-219.

*Pryor, L. R., Miller, J. D., \& Gaughan, E. T. (2009). Testing two alternative pathological personality measures in the assessment of psychopathy: An examination of the SNAP and DAPP-BQ. Journal of Personality Disorders, 23, 85-100.

Raskin, R., \& Terry, H. (1988). A principalcomponents analysis of the Narcissistic Personality Inventory and further evidence of its construct validity. Journal of Personality and Social Psychology, 54, 890-902.

*Ray, J. V., Poythress, N. G., Weir, J. M., \& Rickelm, A. (2009). Relationships between psychopathy and impulsivity in the domain of self-reported personality traits. Personality and Individual Differences, 46, 83-87.

*Rilling, J. K., Glenn, A. L., Jairam, M. R., Pagnoni, G., Goldsmith, D. R., Elfenbein, H., . . . Lilienfeld, S. O. (2007). Neural correlates of social cooperation and non-cooperation as a function of psychopathy. Biological Psychiatry, 61, 1260-1271.

Rosenthal, S. A., \& Hooley, J. M. (2010). Narcissism assessment in social-personality research: Does the association between narcissism and psychological health result from a confound with selfesteem? Journal of Research in Personality, 44, 453-465.

*Ross, S. R., Benning, S. D., Patrick, C. J., Thompson, A., \& Thurston, A. (2009). Factors of the Psychopathic Personality Inventory: Criterionrelated validity and relationship to the BIS/BAS and Five-Factor Models of personality. Assessment, 16, 71-87.

*Ross, S. R., Molto, J., Poy, R., Segarra, P., Pastor, M. C., \& Montanes, S. (2007). Gray's model and psychopathy: BIS but not BAS differentiates primary from secondary psychopathy in noninstitutionalized young adults. Personality and Individual Differences, 43, 1644-1655.
*Schmeelk, K. M., Sylvers, P., \& Lilienfeld, S. O. (2008). Trait correlates of relational aggression in a nonclinical sample: $D S M-I V$ personality disorders and psychopathy. Journal of Personality Disorders, 22, 269-283.

Schmitt, W. A., \& Newman, J. P. (1999). Are all psychopathic individuals low-anxious? Journal of Abnormal Psychology, 108, 353-358.

*Seibert, L. A., Miller, J. D., Few, L. R., Zeichner, A., \& Lynam, D. R. (in press). An examination of the structure of self-report psychopathy measures and their relations with general traits and externalizing behaviors. Personality Disorders: Theory, Research, and Treatment.

*Sellbom, M., Ben-Porath, Y. S., Lilienfeld, S. O., Patrick, C. J., \& Graham, J. R. (2005). Assessing psychopathic personality traits with the MMPI-2. Journal of Personality Assessment, 85, 334-343.

*Sellbom, M., \& Verona, E. (2007). Neuropsychological correlates of psychopathic traits in a nonincarcerated sample. Journal of Research in Personality, 41, 276-294.

Skeem, J. L., \& Mulvey, E. P. (2001). Psychopathy and community violence among civil psychiatric patients: Results from the MacArthur Violence Risk Assessment Study. Journal of Consulting and Clinical Psychology, 69, 358-374.

Taylor, J., \& Lang, A. R. (2006). Psychopathy and substance use disorders. In C. J. Patrick (Ed.), Handbook of psychopathy (pp. 495-511). New York: Guilford Press.

*Uzieblo, K., Verschuere, B., \& Crombez, G. (2007). The Psychopathic Personality Inventory: Construct validity of the two-factor structure. Personality and Individual Differences, 43, 657-667.

*Uzieblo, K., Verschuere, B., Van den Bussche, E., \& Crombez, G. (2010). The validity of the Psychopathic Personality Inventory-Revised in a community sample. Assessment, 17, 334-346.

Vaidyanathan, U., Patrick, C. J., \& Bernat, E. M. (2009). Startle reflex potentiation during aversive picture viewing as an indicator of trait fear. Psychophysiology, 46, 75-85.

*Vaughan, M. G., Newhill, C. E., DeLisi, M., Beaver, K. M., \& Howard, M. O. (2008). An investigation of psychopathic features among delinquent girls. Youth Violence and Juvenile Justice, 6, 240255.

Verona, E., Patrick, C. J., \& Joiner, T. T. (2001). Psychopathy, antisocial personality, and suicide risk. Journal of Abnormal Psychology, 104, 462470.

Walters, G. D., Knight, R. A., Grann, M., \& Dahle, K. (2008). Incremental validity of the Psychopathy Checklist facet scores: Predicting release outcome in six samples. Journal of Abnormal Psychology, 117, 396-405. 
Williams, K. M., Paulhus, D. L., \& Hare, R. D. (2007). Capturing the four-factor structure of psychopathy in college students via self-report. Journal of Personality Assessment, 88, 205-219.

*Wilson, L., Miller, J. D., Zeichner, A., Lynam, D. R., \& Widiger, T. A. (2010). An examination of the validity of the Elemental Psychopathy Assessment: Relations with other psychopathy measures, aggression, and externalizing behaviors. Manuscript in preparation.

*Witt, E. A., Donnellan, M. B., \& Blonigen, D. M. (2009). Using existing self-report inventories to measure the psychopathic personality traits of fearless dominance and impulsive antisociality. Journal of Research in Personality, 43, 1006-1016.

*Witt, E. A., Donnellan, M. B., Blonigen, D. M., \& Krueger, R. F., \& Conger, R. D. (2009). Assess- ment of fearless dominance and impulsive antisociality via normal personality measures: Convergent validity, criterion validity, and developmental change. Journal of Personality Assessment, 91, 265-276.

*Witt, E. A., Hopwood, C. J., Morey, L. C., Markowitz, J. C., McGlashan, T. H., Grilo, C. M., \& Donnellan, M. B. (2010). Psychometric characteristics and clinical correlates of NEO-PI-R fearless dominance and impulsive antisociality in the Collaborative Longitudinal Personality Disorders Study. Psychological Assessment, 22, 559-568.

*Zolondek, S., Lilienfeld, S. O., Patrick, C. J., \& Fowler, K. A. (2006). The Interpersonal Measure of Psychopathy: Construct and incremental validity in male prisoners. Assessment, 13, 470-482. 